Please do not remove this page

RMIT

UNIVERSITY

\title{
Carbon monoxide gas sensor based on titanium dioxide nanocrystalline with a langasite substrate
}

Tan, Soo Lin Joy; Wlodarski, Wojtek; Kalantar-Zadeh, Kourosh; Livingston, Peter

https://researchrepository.rmit.edu.au/esploro/outputs/9921862788501341/filesAndLinks?institution=61RMIT_INST\&index=null

Tan, S. L. J., Wlodarski, W., Kalantar-Zadeh, K., \& Livingston, P. (2006). Carbon monoxide gas sensor based on titanium dioxide nanocrystalline with a langasite substrate. IEEE Sensors 2006, Proceedings, 228-231. https://doi.org/10.1109/ICSENS.2007.355763

Published Version: https://doi.org/10.1109/ICSENS.2007.355763

Repository homepage: https://researchrepository.rmit.edu.au

(c) 2006 IEEE. Personal use of this material is permitted. However, permission to reprint/republish this material for advertising or promotional purposes or for creating new collective works for resale or redistribution to servers or lists, or to reuse any copyrighted component of this work in other works must be obtained from the IEEE.

Downloaded On 2023/04/26 23:43:59 +1000 


\section{Carbon Monoxide Gas Sensor Based on Titanium Dioxide Nanocrystalline with a Langasite Substrate}

\author{
Joy Tan, Wojtek Wlodarski and \\ Kourosh Kalantar-Zadeh \\ School of Electrical and Computer Engineering \\ RMIT University \\ Melbourne, Australia \\ Email: joytan@ieee.org
}

\author{
Peter Livingston \\ Industrial Research Institute, Bioengineering Group \\ Swinburne University of Technology \\ Hawthorn, Australia
}

\begin{abstract}
Titanium dioxide $\left(\mathrm{TiO}_{2}\right)$ and gold doped $\mathrm{TiO}_{2}(\mathrm{Au}-$ $\mathrm{TiO}_{2}$ ) thin films on langasite (LGS) substrates were employed for carbon monoxide (CO) sensing. These two types of sensors have interdigital electrodes with $\mathrm{Ti}, \mathrm{Ni}$ and $\mathrm{Au}$ metallization film. Thin films of $\mathrm{TiO}_{2}$ were deposited using the radio frequency (RF) magnetron sputtering method. Both $\mathrm{TiO}_{2}$ and $\mathrm{Au}-\mathrm{TiO}_{2}$ based gas sensors were exposed to low concentrations of $\mathrm{CO}$ gas in synthetic air at a temperature range between $230{ }^{\circ} \mathrm{C}$ and $320^{\circ} \mathrm{C}$ and their electrical conductivity were measured. It has been observed that the device sensitivity is much greater for the $\mathrm{Au}-\mathrm{TiO}_{2}$ based gas sensor. The response time of the sensor is shorter than that of commercial conductometric CO sensors.
\end{abstract}

\section{INTRODUCTION}

Due to the rapid growth in industries and population, environmental health hazards are a growing concern for our society today. There is a need to monitor and reduce harmful gases e.g. carbon monoxide, nitrogen oxides and hydrocarbons from power plants and automobiles using reliable and low-cost methods. Solid-state gas sensors offer a low-cost and practical alternative to conventional analytic equipment. Particularly, metal-oxide gas sensors are of interest due to their high sensitivity and small dimension.

Titanium dioxide $\left(\mathrm{TiO}_{2}\right)$ is one of the semiconductor metal oxides suitable for development of conductometric gas sensors. Being one of the most investigated materials, $\mathrm{TiO}_{2}$ has been extensively used in gas sensing experiments [1-5]. $\mathrm{TiO}_{2}$ has also found itself to be commercially viable in photocatalytic products e.g. air cleaners and air conditioners and self-cleaning surfaces [6].

$\mathrm{TiO}_{2}$ has three polymorphs namely anatase, rutile and brookite. These different polymorphs influence the sensing properties. The anatase phase is preferred over rutile in gas sensing due to its higher photocatalytic activity [7]. Anatase and brookite are thermodynamically metastable forms of $\mathrm{TiO}_{2}$ which irreversibly convert to rutile at high temperatures. This antase-to-rutile transition has a severe effect on the sensor's sensitivity. Therefore, it is essential to maintain the nanostructure in anatase phase to increase the device's sensitivity in gas sensing [8].

The addition of dopants to metal oxide semiconductors is the most common approach to control the selectivity and sensitivity in gas sensing experiments. Recently, gold has earned its reputation as an excellent catalyst in gas sensing performances. Much literature have reported that the ultra fine particles of gold resulted in a higher catalytic oxidation of $\mathrm{CO}[9,10]$. This catalytic activity is also affected by the anatase phase of $\mathrm{TiO}_{2}$. Takaoka et al. [11] have revealed that the anatase phase has more oxygen vacancies than the rutile phase of $\mathrm{TiO}_{2}$ which lead to more $\mathrm{Ti}^{3+}$ states. Therefore, the catalytic oxidation of $\mathrm{CO}$ is enhanced when gold was supported on the anatase phase.

Langasite (LGS) is a material which has excellent stability at high temperature and, to best of the authors' knowledge, has not previously been used as a conductometric substrate for gas sensing applications.

In this paper, we use the radio frequency (RF) magnetron sputtering method for the fabrication of nanocrystallite thin films of $\mathrm{TiO}_{2}$ on a LGS substrate. Microstructural characterization of the films was carried out by means of scanning electron microscopy (SEM) and X-ray diffraction (XRD). Electrical responses of both sputtered $\mathrm{TiO}_{2}$ and gold doped $\mathrm{TiO}_{2}\left(\mathrm{Au}-\mathrm{TiO}_{2}\right)$ films towards $\mathrm{CO}$ at a temperature range between $230^{\circ} \mathrm{C}$ and $320^{\circ} \mathrm{C}$ have been measured.

\section{EXPERIMENTAL}

\section{A. Fabrication}

Two types of sensor were fabricated on a LGS substrate using photolithography. Sensors have interdigital electrodes with $\mathrm{Ti}, \mathrm{Ni}$ and $\mathrm{Au}$ (in order of deposition) metallization film thicknesses of $20 \mathrm{~nm}, 30 \mathrm{~nm}$ and $50 \mathrm{~nm}$, respectively. Each sensor consists of 113 electrode pairs, aperture width of $5600 \mu \mathrm{m}$ and an electrode width of $8.5 \mu \mathrm{m}$. $\mathrm{TiO}_{2}$ films were prepared using a $99.9 \%$ pure Ti target by RF magnetron 
sputtering in an $\mathrm{Ar}(60 \%)$ and $\mathrm{O}_{2}(40 \%)$ mixture for 40 minutes at room temperature. A chamber pressure of $1 \times 10^{-2}$ Ti target by RF magnetron sputtering in an $\mathrm{Ar}(60 \%)$ and $\mathrm{O}_{2}$ $(40 \%)$ mixture for 40 minutes at room temperature. A chamber pressure of $1 \times 10^{-2}$ Torr and RF power of $140 \mathrm{~W}$ were used for sputtering. The sputtered films have a thickness of $\sim 100 \mathrm{~nm}$. On one type of sensor, a thin layer of $\mathrm{Au}$ was sputtered for 10 seconds.

\section{B. Morphological and Structural Characterization}

For SEM characterization, a thin layer of $\mathrm{Au}$ was sputtered on the $\mathrm{TiO}_{2}$ films. The $\mathrm{TiO}_{2}$ films were deposited for 7 hours and 40 minutes. This was conducted to obtain a sufficiently thick layer for XRD measurements. Both nonannealed and annealed (at $500^{\circ} \mathrm{C}$ ) bare LGS substrates with $\mathrm{TiO}_{2}$ films are shown in Fig. 1 and Fig. 2 respectively. Fig. 1 shows a denser amorphous $\mathrm{TiO}_{2}$ film and consists of pyramidal shaped grains. Significant grain coarsening, less elongated and edge rounded shaped grains are shown in Fig. 2.

Both nonannealed and annealed (at $500^{\circ} \mathrm{C}$ ) LGS with $\mathrm{Ti}$, $\mathrm{Ni}$ and $\mathrm{Au}$ metallization film (LGS-TiNiAu) substrates are shown in Fig. 3 and Fig. 4 respectively. Fig. 3 consists of a compact and homogeneous polycrystalline nanostructure and the grain size is approximately $100 \mathrm{~nm}$. Fig. 4 shows that the anatase structure is changed after annealing at $500^{\circ} \mathrm{C}$. Slight grain coalescence occurred during annealing. There is the presence of spherical particles surrounded by larger grains. There is no significant grain growth in the spherical particles. Guidi et al. [12] reported that the grain coalescence is almost certainly due to the anatase-to-rutile transition and that the small particles of the cluster were $\mathrm{TiO}_{2}$ anatase and the larger grains were $\mathrm{TiO}_{2}$ rutile.

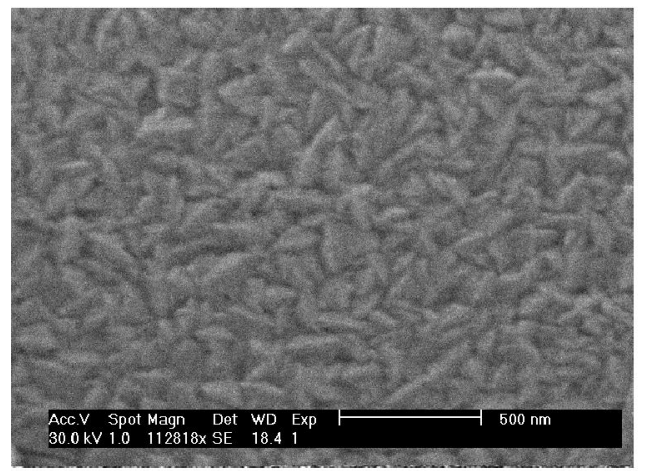

Figure 1. SEM image of a $\mathrm{TiO}_{2}$ film on nonannealed bare LGS substrate.

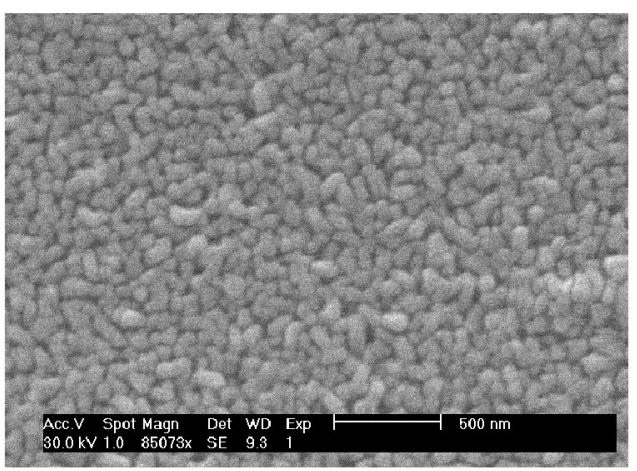

Figure 2. SEM image of a $\mathrm{TiO}_{2}$ film on annealed (at $500^{\circ} \mathrm{C}$ ) bare LGS substrate.

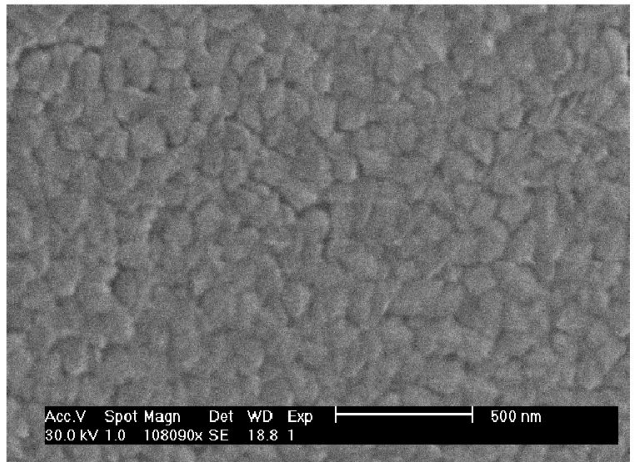

Figure 3. SEM image of a $\mathrm{TiO}_{2}$ film on nonannealed LGS-TiNiAu substrate.

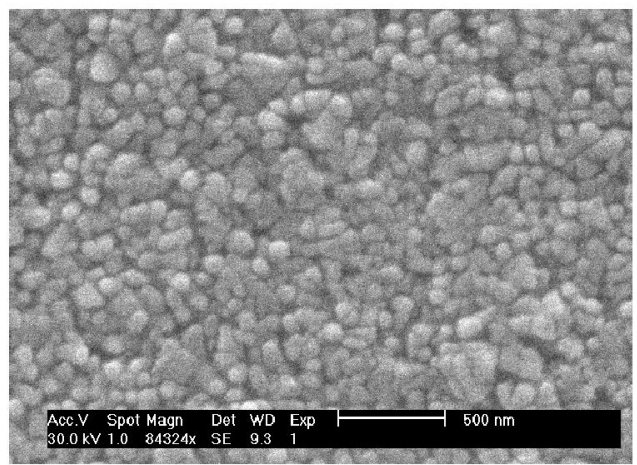

Figure 4. SEM image of a $\mathrm{TiO}_{2}$ film on annealed (at $500^{\circ} \mathrm{C}$ ) LGS-TiNiAu substrate.

The XRD patterns of $\mathrm{TiO}_{2}$ films were obtained using a Bruker D8 Advance XRD with a CuK $\alpha$ source. The analysis was performed to understand the growth of $\mathrm{TiO}_{2}$ films on the nonannealed LGS substrates. The XRD patterns of both bare LGS and LGS-TiNiAu substrates are shown in Fig. 5 and Fig. 6 respectively. Both substrates have a $\mathrm{TiO}_{2}$ film deposited for 7 hours and 40 minutes. 
The XRD pattern in Fig. 5 shows several anatase peaks for the bare LGS substrate. For the LGS-TiNiAu substrate, there is an increase number of anatase peaks in Fig. 6 as compared with Fig. 5. The anatase peaks in Fig. 6 are observed to be slightly broader. An intense peak due to anatase (112) was observed in the $2 \theta$ range at $38.5^{\circ}$. This significant increase of the intensity is accompanied by the decrease of anatase (101). Similar anatase phases i.e. (101), (112), (200) and (211) were also reported in [13]. The other peaks in Fig. 6 correspond to the gold electrodes and LGS substrate.

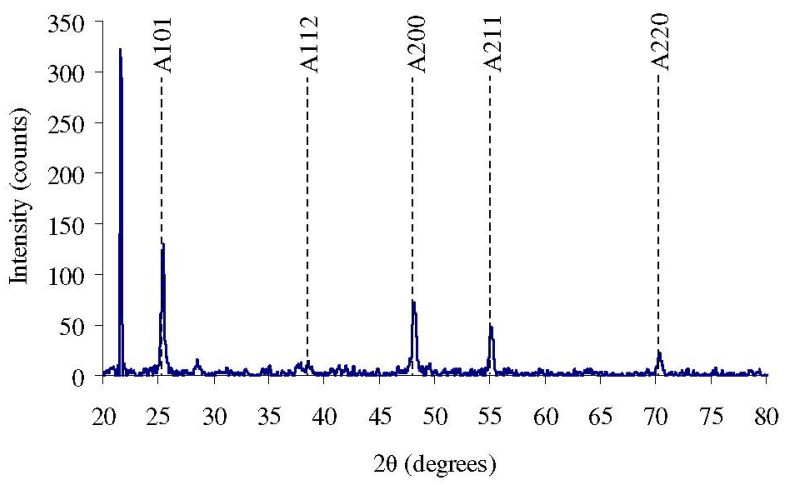

Figure 5. XRD pattern of the anatase (A) peaks from a bare LGS substrate.

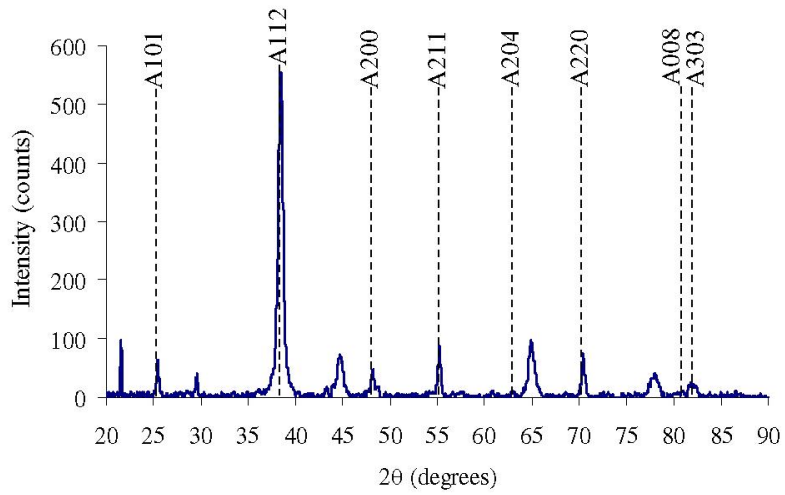

Figure 6. XRD pattern of the anatase (A) peaks from a LGS-TiNiAu substrate.

\section{Gas Sensing Measurements}

Both $\mathrm{TiO}_{2}$ and $\mathrm{Au}-\mathrm{TiO}$, thin films on LGS-TiNiAu substrates were tested separately. Each conductometric sensor was mounted on an alumina microheater. The microheater was controlled by a regulated DC power supply providing different operating temperatures. The output resistance as a function of time across the conductometric sensor during $\mathrm{CO}$ exposure was measured using a multimeter (Keithley 2001). A computerized gas calibration system, with mass flow controllers, was used to expose the sensor to different concentrations of $\mathrm{CO}$ gas. The total flow rate was kept constant at $200 \mathrm{sccm}$ and synthetic air was used as the reference gas.

\section{RESUlTS AND DISCUSSION}

The change in conductance of $\mathrm{TiO}_{2}$ and $\mathrm{Au}-\mathrm{TiO}_{2}$ thin films on LGS-TiNiAu substrates were examined in 60 and $125 \mathrm{ppm}$ of $\mathrm{CO}$ in synthetic air at a temperature range between $230^{\circ} \mathrm{C}$ and $320^{\circ} \mathrm{C}$. It has been observed that the device sensitivity is much greater for the $\mathrm{Au}-\mathrm{TiO}_{2}$ based gas sensor.

The response of the sensor is defined as a ratio of resistance in synthetic air to the resistance when exposed to the target gas. In Fig. 7, the $\mathrm{Au}-\mathrm{TiO}_{2}$ sensor showed fast response and recovery time of less than 20 seconds towards 60 and $125 \mathrm{ppm}$ of $\mathrm{CO}$ at $318^{\circ} \mathrm{C}$, respectively. The $\mathrm{Au}-\mathrm{TiO}_{2}$ sensor also had a good repeatability in Fig. 8. The Au-TiO sensor exhibited the largest response towards $125 \mathrm{ppm}$ of $\mathrm{CO}$ at $230^{\circ} \mathrm{C}$ as shown in Fig. 9. The $\mathrm{Au}-\mathrm{TiO}_{2}$ sensor response was 3 to 5 times larger than that of the $\mathrm{TiO}_{2}$ sensor, with the ratio varying with temperature. It is observed in Fig. 10 that by increasing the operational temperature, the $\mathrm{Au}-\mathrm{TiO}_{2}$ sensor response becomes smaller for both 60 and $125 \mathrm{ppm}$ of $\mathrm{CO}$.

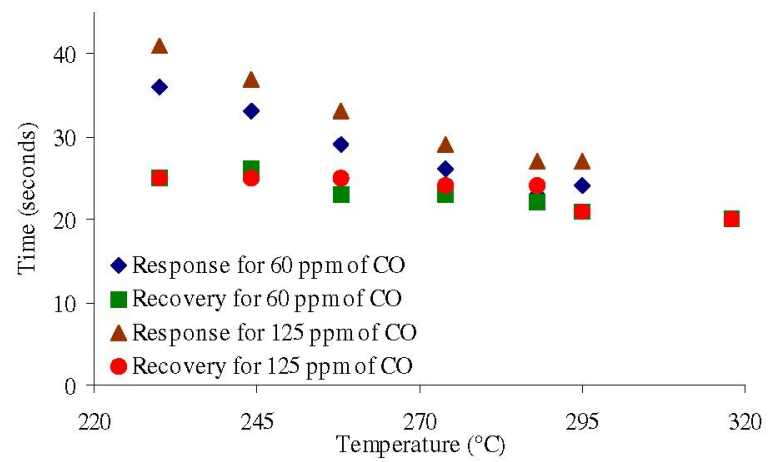

Figure 7. Response and recovery times of $\mathrm{Au}_{-} \mathrm{TiO}_{2}$ sensor towards 60 and $125 \mathrm{ppm}$ of $\mathrm{CO}$ for different temperatures.

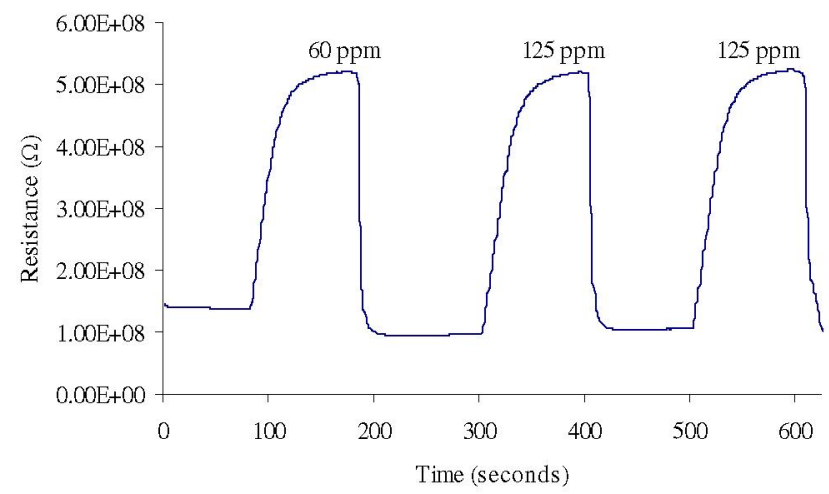

Figure 8. Response of $\mathrm{Au}-\mathrm{TiO}_{2}$ sensor towards 60 and $125 \mathrm{ppm}$ of $\mathrm{CO}$ at $230^{\circ} \mathrm{C}$. 


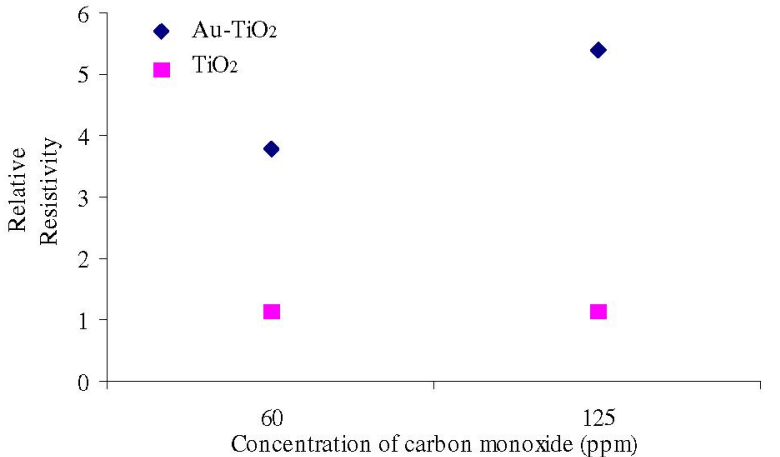

Figure 9. Comparison of responses for $\mathrm{TiO}_{2}$ and $\mathrm{Au}-\mathrm{TiO}_{2}$ sensors towards 60 and $125 \mathrm{ppm}$ of $\mathrm{CO}$ at $230^{\circ} \mathrm{C}$.

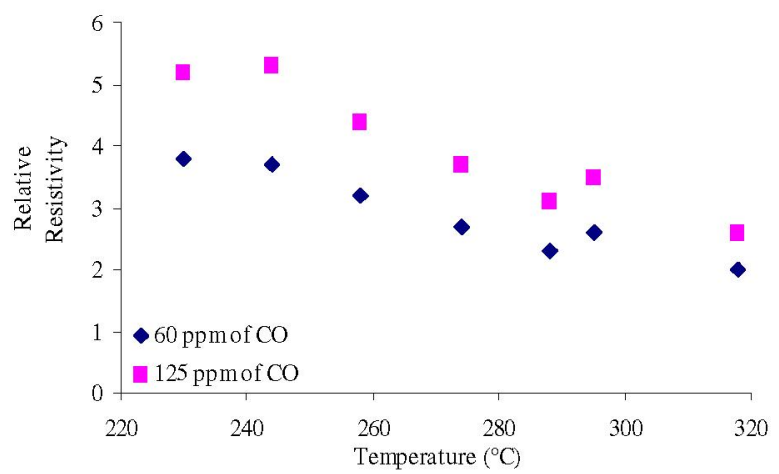

Figure 10. Response of $\mathrm{Au}^{-\mathrm{TiO}_{2}}$ sensor towards 60 and $125 \mathrm{ppm}$ of $\mathrm{CO}$ from $230^{\circ} \mathrm{C}$ to $320^{\circ} \mathrm{C}$

\section{CONCLUSION}

Thin films of anatase $\mathrm{TiO}_{2}$ have been deposited on LGSTiNiAu substrates using the RF magnetron sputtering method and successfully used as conductometric CO sensors. The SEM images show the compactness and homogeneous polycrystalline nanostructure for the as deposited $\mathrm{TiO}_{2}$ film on the LGS-TiNiAu substrate. A grain size of approximately $100 \mathrm{~nm}$ was achieved. The XRD patterns also depict the nanostructure of the as deposited $\mathrm{TiO}_{2}$ film with a slight broadening of the anatase peaks. The $\mathrm{Au}-\mathrm{TiO}_{2}$ sensor has shown to enhance its sensitivity by 3 to 5 times as compared to the $\mathrm{TiO}_{2}$ sensor. The $\mathrm{Au}-\mathrm{TiO}_{2}$ sensor also demonstrated the largest response towards $125 \mathrm{ppm}$ of $\mathrm{CO}$ at $230^{\circ} \mathrm{C}$. The increase in sensitivity of the sensor towards $\mathrm{CO}$ gas can be attributed to the addition of gold on the surface of $\mathrm{TiO}_{2}$ which acts as a catalyst. As compared to other metal types of doping on $\mathrm{TiO}_{2}$ films, our work has shown that the $\mathrm{Au}-\mathrm{TiO}_{2}$ sensor displayed a relatively fast response and recovery time of less than 20 seconds towards 60 and $125 \mathrm{ppm}$ of $\mathrm{CO}$ at $318^{\circ} \mathrm{C}$.

\section{REFERENCES}

[1] L. Sun, H. Zhao, S. Gao, and J. Zhao, "Preparation and gas-sensing property of a nanosized titania thin film towards alcohol gases," Sens. Actuators, B, vol. 114, pp. 387-391, 2006.

[2] F. H. Babaei, M. Keshmiri, M. Kakavand, and T. Troczynski, "A resistive gas sensor based on undoped p-type anatase," Sens. Actuators, B, vol. 110, pp. 28-35, 2005.

[3] O. K. Varghese, D. Gong, M. Paulose, K. G. Ong, and C. A. Grimes, "Hydrogen sensing using titania nanotubes," Sens. Actuators, B, vol. 93, pp. 338-344, 2003.

[4] M. L. Frank, M. D. Fulkerson, B. R. Patton, and P. K. Dutta, "TiO ${ }_{2-}^{-}$ based sensor arrays modeled with nonlinear regression analysis for simultaneously determining $\mathrm{CO}$ and $\mathrm{O}_{2}$ concentrations at high temperatures," Sens. Actuators, B, vol. 87, pp. 471-479, 2002.

[5] A. Rothschild, F. Edelman, Y. Komem, and F. Cosandey, "Sensing behavior of $\mathrm{TiO}_{2}$ thin films exposed to air at low temperatures," Sens. Actuators, B, vol. 67, pp. 282-289, 2000.

[6] A. Fujishima and X. Zhang, "Titanium dioxide photocatalysis: present situation and future approaches," C. R. Chimie, vol. 9, pp. 750-760, 2006.

[7] N. Ruzycki, G. S. Herman, L. A. Boatner, and U. Diebold, "Scanning tunneling microscopy study of the anatase $\left(\begin{array}{lll}1 & 0 & 0\end{array}\right)$ surface," Surf. Sci., vol. 529, pp. 239-244, 2003.

[8] M. C. Carotta et al., "Gas sensors based on semiconductor oxides: basic aspects onto materials and working principles," Mater. Res. Soc. Symp. Proc., vol. 828, pp. A4.6.1-A4.6.11, 2005.

[9] L. Fan, N. Ichikuni, S. Shimazu, and T. Uematsu, "Preparation of $\mathrm{Au} / \mathrm{TiO}_{2}$ catalysts by suspension spray reaction method and their catalytic property for CO oxidation," Appl. Catal., A, vol. 246, pp. 87$95,2003$.

[10] T. V. Choudhary and D. W. Goodman, "Oxidation catalysis by supported gold nano-clusters," Top. Catal., vol. 21, 2002.

[11] G. H. Takaoka, T. Hamano, K. Fukushima, J. Matsuo, and I. Yamada, "Preparation and catalytic activity of nano-scale Au islands supported on $\mathrm{TiO}_{2}$," Nucl. Instrum. Methods Phys. Res., Sect. B, vol. 121, pp. 503-506, 1997.

[12] V. Guidi, M. C. Carotta, M. Ferroni, G. Martinelli, and M. Sacerdoti, "Effect of dopants on grain coalescence and oxygen mobility in nanostructured titania anatase and rutile," J. Phys. Chem. B, vol. 107, pp. 120-124, 2003.

[13] T. Y. Yang, H. M. Lin, B. Y. Wei, C. Y. Wu, and C. K. Lin, "UV enhancement of the gas sensing properties of nano- $\mathrm{TiO}_{2}, " \mathrm{Rev} . \mathrm{Adv}$. Mater. Sci., vol. 4, pp. 48-54, 2003. 